\title{
Anselmo Peres Alós - A letra, o corpo e o desejo: masculinidades subversivas no romance latino-americano
}

Florianópolis. Editora Mulheres, 2013

Thiago Moreira Aguiar ${ }^{1}$

Pensar em questões relacionadas à sexualidade, à sua abrangência e ao preconceito histórico que a envolve invariavelmente constitui um conjunto de embates problemáticos e geralmente pouco esclarecidos sobre o tema. Atualmente, de forma geral, este assunto anda ainda muito acanhado no próprio meio acadêmico, no qual são poucos os docentes que trabalham e discutem esta questão. Tal preconceito faz com que não só o assunto fique a portas fechadas, mas que a própria sexualidade fique atrás dessas portas ou, como já foi cunhado popularmente, dentro do armário.

Doutor em literatura comparada pelo Programa de Pós-Graduação em Letras da Universidade Federal do Rio Grande do Sul (UFRGS) e professor adjunto no Departamento de Letras Vernáculas da Universidade Federal de Santa Maria (UFSM), Anselmo Peres Alós articula em seu livro uma aprofundada discussão sobre a sexualidade na literatura, a partir da análise de três romances latino-americanos: Onde andará Dulce Veiga?, do brasileiro Caio Fernando Abreu; No se lo digas a nadie, do peruano Jaime Bayly, e El beso de la mujer araña, do argentino Manuel Puig. Em uma obra ousada, teórica e epistemologicamente orgânica, Anselmo Peres Alós traça um perfil da subjetividade dos personagens criados por estes autores, buscando um contraponto entre os comportamentos individuais e as representações das respectivas identidades nacionais. Partindo de noções como intertextualidade, representação de gênero e da orientação sexual dos personagens apresentados nos romances, vinculados com uma suposta estruturação de um corpo social homogêneo nacional, constituiu-se o teor de sua análise comparatista.

Com uma leitura/escrita assumidamente comprometida, Anselmo Peres Alós propõe uma análise de como se articulam os romances latino-americanos aqui citados, a partir das práticas sexuais de

\footnotetext{
${ }^{1}$ Mestrando em estudos literários na Universidade Federal de Santa Maria (UFSM), Santa Maria, RS, Brasil. E-mail: thiagomoreira.aguiar@gmail.com
} 
personagens que fogem do modelo heteronormativo canônico. Nesse sentido, o foco investigativo recai, principalmente, na direção dos personagens homossexuais masculinos, que representam identidades excluídas, subalternas e que são obrigados a negociar nesse campo supostamente harmonioso, representados aqui pela pertença nacional. Contudo, mesmo que nesse conteúdo aqui citado já se possa perceber uma ruptura com as tradições literárias tradicionais, a pesquisa não se constitui apenas sob esses eixos temáticos, os quais também são trabalhados por outras áreas do conhecimento nas ciências humanas. Ainda há mais coisas por sair do armário.

Em A letra, o corpo e o desejo, publicado em 2013 pela Editora Mulheres, de Florianópolis, o autor nos apresenta uma inovadora busca por uma poética sexual que, segundo ele, mensura um modo de atuação na composição de um capital cultural, partindo de uma análise do corpus dos três romances. Por conseguinte, é lançada a hipótese (confirmada ao longo da obra) de que há uma teoria implícita oculta nessas narrativas e que rompem, através de uma estrutura comum, com o paradigma heteronormativo. É importante salientar que a noção de homotextualidade também é observada pelo autor, mas acaba sendo preterida justamente por conter certo essencialismo à concepção de identidade homossexual, o que difere das suas interpretações.

Com uma perspectiva engajada pela teoria queer, de matriz anglosaxônica, o autor defende a ideia de que a gênese da orientação sexual ou a identidade sexual dos indivíduos são formadas pelos discursos sociais, nas suas construções simbólicas. Dessa forma, cai por terra a concepção de uma suposta normalidade sexual pautada pela sentença biológica, com formas sociais unívocas e regidas pelo paradigma da teoria do gênero. Além disso, o conceito de performatividade ganha importante relevo em sua proposta. Colocando-se através da literatura, ela é entendida como forma de propagação, tanto de um ideário de identidades nacionais, exemplo trabalhado no livro, como por uma forma política de resistência, de caráter subversivo.

Tendo em vista o instante em que os romances foram publicados (décadas de 1970 a 1990), compreendidos historicamente em períodos nos quais foram vividos momentos de ditaduras militares e redemocratizações, pode-se observar um crescimento do postulado de Estado-nação, fortemente marcado e propagado. $\mathrm{O}$ que se catequisa nesses discursos políticos, de maneira geral, é um Estado coeso, 
imbuído na mesma premissa: branca, heterossexual, forte, religiosa etc. Contudo, este discurso político não visualiza as tensões existentes na morfologia social, na qual sentimentos, desejos, corpos, normas e culturas convivem em um regime de trocas, aceitações e preconceitos vários. Anselmo Peres Alós vê nas obras de Caio, Puig e Bayly outro tipo de discurso que vai na contracorrente dos pressupostos hegemônicos e que desnuda outra sinergia social, trazendo à tona estratégias de visibilidade dos que não se enquadram no perfil estereotipado socialmente.

No romance Onde andarás Dulce Veiga?, de Caio Fernando Abreu, Anselmo Peres Alós visualiza de forma mais clara essa disjunção cotidiana. Em um meio heteronormativo, no qual a conceptualização subjetiva é dada de forma binária para o sexo, o narrador-protagonista do romance representa a contestação dessas postulações prontas e impostas na sociedade. A começar por não ter sequer um nome, recurso mínimo para uma identidade, ele também não consegue se ver representado em nenhum modelo identitário que lhe é sugerido: não se vê como homossexual, nem como heterossexual.

Compactuando com Judith Butler e a sua teoria da heteronormatividade, Anselmo Peres Alós percebe no personagem Molina, de El beso de la mujer araña, de Manuel Puig, o rompimento dessa gênese, na medida em que o personagem se vê e se afirma como uma mulher, rejeitando o determinismo biológico. Além disso, ele trai a sua pátria em nome de um amor por outro homem, o que não deixa de ser compreensível uma vez que ele não se sente integrante do modelo identitário propagado por sua nação. Dessa forma, ele desafia a ordem hegemônica ao questionar tal postulação hierárquica e binária do sexo, traindo justamente o que simboliza a maior unidade social.

Por fim, na obra de Jaime Bayly, No se los digas nadie, o personagem Joaquim Camilo representa a alta classe peruana, figurando foco narrativo diverso em relação aos outros dois romances. Camilo vive em um contexto familiar de extrema repressão, tendo uma religiosa fervorosa como mãe e um pai extremamente machista, o personagem vive uma extensão da própria sociedade dentro de sua casa. Nesse sentido, ele opõe-se não só ao cárcere familiar, mas às principais estruturas heteronormativas que são representadas pelo pai e pela mãe, assim como também aos amigos que não têm a mesma coragem de se assumir como gays, enfrentando o sistema. 
Esta breve interpretação dos três romances, retirada de forma absolutamente rasa e superficial do que de fato é trabalhado em A letra, o corpo $e$ o desejo, serve apenas como uma ilustração branda dos ideologemas que serão configurados na obra, caracterizando os eixos de análise configurados no título do livro. Nesse sentido, a letra representaria o próprio discurso literário e suas implicações políticas. Concebidas através da performatividade, as narrativas possuiriam um potencial de mudança (ou ao contrário, de afirmação) nas concatenações de identidade sexual e de gênero. Dessa forma, a literatura articula-se marcadamente com a teoria queer. Temos o corpo, que não seria marcado pela materialidade biológica, operacionalizado como instrumento de resistência à heteronormatividade, aos seus discursos e seus paradigmas. E por fim temos o desejo, um desejo que não se dá pela libido, mas pela pura e simples vontade de ser reconhecido nas especificidades que constituem os indivíduos como sujeitos sexuais que, via de regra, encontram-se condenados a uma cidadania de segunda categoria.

Dessa forma, a importância e a compreensão do processo de constituição do sujeito- aparentemente tão fácil e banal - cria uma necessidade de se debruçar em uma análise que contemple os contrários, se afaste de uma ideia linear, seja ela qual for. A leitura que Anselmo Peres Alós faz dos três romances não somente procura colocar para fora o que está dentro do armário, como parece também inverter a própria lógica, fechando as portas para o discurso heteronormativo. Contudo, para compreender a "chave" do que se abre e fecha na obra, exige-se a aceitação natural de um sincretismo regente nas relações intersubjetivas. Nesse sentido, é primordial uma consciência de alteridade, como argumenta Anselmo Peres Alós: “[é] necessário repensar o estatuto do eu fora dos domínios do mesmo, compreender o sujeito como a construção de interesse(s) e, finalmente, aceitar que o eu que fala é desde sempre um outro marcado pela alteridade, isso é, pela impossibilidade de completude" (p. 38).

O convite para a leitura configura-se a partir de questões complexas que permeiam nosso cotidiano e que são tratadas por Anselmo Peres Alós com grande profundidade e muita clareza. Na medida em que a premissa heterossexual é posta em xeque, toda uma sociedade, uma pátria imaginada como tal, se debilita, estremece, emergindo suas limitações, costumes tradicionais se transformam. Quando Michel Maffesoli, em A parte do diabo, refere-se à pós-modernidade em que 
vivemos e à sabedoria integradora da alteridade, tem-se: "Esta sensibilidade em relação ao outro (em si, na natureza, na vida social) leva a uma concepção ampliada da realidade. Realidade plural, polissêmica. Realidade absoluta. A da experiência e a do vivido coletivo" (Maffesoli, 2004, p. 34), mesmo que, segundo o autor, isso seja muito airoso e, não raro, malvisto.

Abreu, Puig e Bayly, colocados em confronto pela leitura de Anselmo Peres Alós, subvertem a percepção das subjetividades que não fazem parte das visões patriarcais de raízes abraãmicas, segundo as quais as religiosidades cristãs, islâmicas e judaicas relegam a sexualidade a morbidade simplista do pecado. Nesse sentido, a homossexualidade dos personagens, mesmo que com suas especificidades para cada romance, abre fissuras nos púlpitos das categorias identitárias, polarizadas em torno do gênero e vividas pela nossa sociedade ocidental e latino-americana. As portas que se abrem nessa obra são as de um armário, figuração simbólica que determina a regulação da vida de gays e lésbicas e que concede aos heterossexuais a primazia dos valores sociais. A título de encerramento e parafraseando o sempre atual Machado de Assis: "Palavra puxa palavra, uma ideia traz a outra, e assim se faz um livro, um governo, ou uma revolução, alguns dizem que assim é que a natureza compôs suas espécies" (Assis, 1997, p. 44). Da mesma forma como palavra puxa palavra, também a madeira chama cupins. Para entender os que estão roendo esse armário, leia A letra, o corpo e o desejo, de Anselmo Peres Alós.

\section{Referências}

ASSIS, Machado de (1997). Histórias sem data. In: ASSIS, Machado de. Primas de Sapucaia. São Paulo: Globo. p. 43-49.

MAFFESOLI, Michel (2004). A parte do diabo: resumo da subversão pós-moderna. Rio de Janeiro: Record. 